\title{
Evidence for multilocus genetic control of preferential fertilisation in maize
}

\author{
Jonathan F. Wendel*, \\ Marlin D. Edwards, and \\ Charles W. Stuber
}

Department of Genetics, North Carolina State

University, Raleigh, NC 27695-7614, U.S.A.

Genetic segregation was studied in more than 1900 seedlings of an $F_{2}$ between the maize (Zea mays $L$.) inbred lines T232 and CM37. Significant segregation distortion was observed at 11 of 17 segregating allozyme loci and at a single morphological marker locus distributed on 7 of the 10 chromosomes in the genome. Deviations from genotypic class expectations were small for most loci, and averaged 7.7 per cent. Percent transmission of the allele contributed by T232 varied from $\mathbf{4 7 . 7}$ per cent to $\mathbf{5 3 . 3}$ per cent. The allele donated by T232 was significantly under-represented for loci on chromosomes 1 and 8, whereas the allele contributed by CM37 was deficient for nine of the ten segregating loci on chromosomes 2,3 , and 6 . In all cases, the parental origin of the deficient allele was consistent for markers on a chromosome. Evidence is presented that suggests the aberrant ratios arose from linkage of the markers with genetic factors affecting prezygotic transmission, and that a minimum of 5 such factors were operative, one on each of chromosomes $1,2,3,6$, and 8 . In contrast to the multi-locus and multi-chromosomal distorted segregation observed in the $F_{2}$, all loci in backcross progenies fit Mendelian expectations. It is suggested that this discrepancy reflects variable environmental selection pressures on genes that influence aspects of gamete competition.

\section{INTRODUCTION}

One of the fundamental tenets of classical Mendelian genetics is that segregation of alternate alleles in a heterozygous individual occurs randomly during gametogenesis, and that the progeny array resulting from the fusion of randomly transmitted gametes is predictable. There are, however, numerous examples of non-random transmission in plants, which are usually detected genetically as distorted segregation of one or more genes in particular progenies (see Grant, 1975). Aberrant segregation ratios in plants may arise from a variety of physiological or genetic causes, and may be manifested as differential transmission in either the male (Bianchi and Lorenzoni, 1975; Mangelsdorf and Jones, 1926; Pfahler, 1975) or female (Longley, 1945; Rhoades, 1952; Rhoades and Dempsey, 1966) germ line, or result from post-zygotic selection prior to genotypic censusing (e.g. Rick, 1963). Most commonly, however, skewed segregation appears to arise from male

* Present address: Department of Botany, Bessey Hall, Iowa State University, Ames, Iowa 50011, U.S.A. gametophytic selection, through selective influences of the gynoecium (Johnson and Mulcahy, 1978; Ottaviano et al., 1982; Pfahler, 1967), the environment (Zamir et al., 1982), or through differential competitive ability of genetically variable pollen (Mangelsdorf and Jones, 1926; Pfahler, 1975; Sprague, 1933). In most cases, the aberrant ratios are restricted to one or a few marker genes that are hypothesised to be linked with unobserved genetic factors influencing some aspect of gamete function (Emerson, 1934; Mangelsdorf and Jones, 1926). The possibility that numerous factors may influence male competitive ability has recently been suggested by selection experiments in maize (Mulcahy, 1974; Ottaviano et al., 1982).

In the course of investigating the genetic control of quantitative trait variation in maize (Edwards et al., 1986; Stuber et al., 1986), an unusual $F_{2}$ progeny arose where skewed segregation ratios were observed for a large proportion of the molecular markers scored. These data are presented here, along with evidence that suggests the aberrant ratios arose through multi-locus and multi-chromosomal gamete competition. 


\section{MATERIALS AND METHODS}

During the summer of $1983, F_{1}$ hybrids between the two inbred lines CM37 and T232 were produced in a field near Clayton, N.C. These lines are divergent in pedigree, morphology, and allozyme genotypes: CM37 is an early-maturing Canadian dent whereas T232 was derived from an admixture of the open-pollinated varieties Jellicorse (a Southern Dent) and Teko Yellow (from South Africa). The two lines are homozygous for different alleles at 17 allozyme loci (Stuber and Goodman, $1983 a$; see table 1). Subsequent to harvest, the hybrids were electrophoretically verified, grown in a winter nursery near Homestead, Fla., and selfed to produce the $F_{2}$ generation. Backcross progenies with T232 were generated in the summer of 1985 in North Carolina, using the $F_{1}$ as both male and female. All families were produced in the cytoplasm contributed by T232.

Starch gel electrophoretic analyses were conducted on etiolated coleoptile tissue of 5-day-old seedlings following established procedures (Cardy et al., 1983; Goodman et al., 1980; Stuber and Goodman, 1983a, 1983b). For the analysis of the $\mathrm{F}_{2}$ progeny, over 1900 seedlings were scored for their genotypes at 17 segregating allozyme loci, and subsequent to transplanting to the field, were additionally scored for the color factor $B$ (Booster). Segregating marker loci were present on seven of the ten maize chromosomes. Parental genotypes, locus symbols, and chromosomal locations of most allozyme loci have been previously detailed (Goodman and Stuber, 1983; Stuber and Goodman 1983a, 1983b; Wendel et al., 1985, 1986), and are reproduced in table 1. Electrophoretic methods and variation patterns for two of the 17 segregating allozyme loci (Tpi-4 and Dia-1) are unpublished. Formal genetic documentation of these markers will be presented in a future communication. Backcross progenies were similarly analysed, although the numbers were smaller $(N=$ 202 and 406 for $F_{1} \times T 232$ and $T 232 \times F_{1}$, respectively) and the seedlings were not transplanted.

Most loci segregated three genotypic classes in the $\mathrm{F}_{2}$ and two classes in the $\mathrm{BC}$ generations. Exceptions are at Booster, where the allele $B$ is dominant to $b$, and at the allozyme loci $M d h-1$, $M d h-5, H e x-1$, and Tpi-4, where only two of the three genotypic classes could be discriminated. These cases are due either to the presence of null variants in one parent (in which case the null/active heterozygous class was pooled with the active homozygous class), or to band overlap with the products of other loci. Booster $(B)$ and Hex-1 were not scored in the $\mathrm{BC}$ progenies.

Segregation at each locus was tested for conformance to Mendelian expectations by chi-square goodness of fit tests. Recombination estimates among linked loci were calculated according to the method of maximum likelihood using the computer program Linkage-1 (Suiter et al., 1983).

Table 1 Chromosomal locations* and parental genotypes of allozyme loci differentiating the maize inbred lines T232 and CM37

\begin{tabular}{|c|c|c|c|c|}
\hline Enzyme & $\begin{array}{l}\text { Locus } \\
\text { symbol }\end{array}$ & $\begin{array}{l}\text { Chromosomal } \\
\text { location }\end{array}$ & $\begin{array}{l}\text { T232 } \\
\text { allele }\end{array}$ & $\begin{array}{l}\text { CM37 } \\
\text { allele }\end{array}$ \\
\hline Acid phosphatase & $A c p-1$ & $9-60$ & 4 & 2 \\
\hline Alcohol dehydrogenase & $A d h-1$ & $1 \mathrm{~L}-127$ & 4 & 6 \\
\hline Aminopeptidase & $A m p-3$ & $5 S-32$ & 3 & 4 \\
\hline Aspartate aminotransferase & Got-2 & $5 \mathrm{~L}-96$ & 4 & 2 \\
\hline Diaphorase & Dia-1 & $2 \mathrm{~S}-27$ & 12 & 8 \\
\hline Esterase & $E-8$ & $3 S-20$ & 4 & 4.5 \\
\hline \multirow[t]{2}{*}{ Hexokinase } & Hex-1 & $3 S-44$ & 4 & $n$ \\
\hline & Hex-2 & $6 \mathrm{~L}-58$ & 2 & 1 \\
\hline Isocitrate dehydrogenase & $I d h-2$ & $6 \mathrm{~L}-101$ & 4 & 6 \\
\hline \multirow[t]{4}{*}{ Malate dehydrogenase } & $M d h-1$ & $8-0$ & 1 & 6 \\
\hline & $M d h-2$ & $6 \mathrm{~L}-103$ & 6 & 3.5 \\
\hline & $M d h-3$ & $3 \mathrm{~L}-121$ & 18 & 16 \\
\hline & $M d h-5$ & $5 S-16$ & 15 & 12 \\
\hline Phosphoglucomutase & $P g m-2$ & $5 S-0$ & 4 & 3 \\
\hline 6-Phosphogluconate dehydrogenase & $P g d-2$ & $3 \mathrm{~L}-71$ & 2.8 & 5 \\
\hline Phosphohexose isomerase & Phi-1 & $1 \mathrm{~L}-139$ & 4 & 5 \\
\hline Triose phosphate isomerase & Tpi-4 & $3 S-61$ & $n$ & 4 \\
\hline
\end{tabular}

* Approximate map positions are indicated, where $\mathrm{L}$ and $\mathrm{S}$ refer to the long and short arms, respectively. Acp-1 and $M d h-1$ are near the centromeres of their respective chromosomes (arm not known). Recombination distance (in cM) between any two markers on a chromosome is equal to the difference in their map positions; $v i z, T p i-4$ (3S-61) and Pgd-2 (3S-71) recombine with a frequency of 10 per cent. 


\section{RESULTS AND DISCUSSION}

Recombination estimates between all pairs of linked loci in the $\mathrm{F}_{2}$ and $\mathrm{BC}$ families were calculated and compared to previously published data (Goodman et al., 1980; Goodman and Stuber, 1983; Wendel et al., 1985, 1986). All linkage estimates were statistically homogeneous (data not presented), indicating no significant recombinational differences among the families.

Segregation data for all loci in the $F_{2}$ and backcross generations are presented in table 2 . In the $F_{2}$ progeny, observed segregations for all but six loci significantly departed from expectations $(p<0 \cdot 10)$. Twelve loci showed aberrant segregation, three at the 10 per cent level, five at the 5 per cent level, and four at the 1 per cent level. The observed magnitude of distortion was generally small, however; the average deviation from genotypic class expectations was $7 \cdot 7$ per cent, and transmission of the T232 allele varied from 47.7 to 53.3 per cent. The ability to detect significant deviations from expectations for some loci was clearly due to the large sample sizes employed. It is likely that with smaller sample sizes fewer cases of distortion would have been observed.

Of particular interest are the chromosomal locations of the markers that displayed skewed segregation, and the parental origins of the deficient alleles. Deviant ratios were observed for nearly all loci on five of the seven marked chromosomes: both segregating loci on chromosomes 1 and 2, four of five markers on chromosome 3 , all three markers on chromosome 6 , and the single segregating locus on chromosome 8 . In contrast, all four markers on chromosome 5 fit Mendelian expectations, as did the single marker on chromosome 9. Furthermore, the deficient parental class varied among the chromosomes, but was consistent for multiple markers on any given chromosome. The allele donated by T232 was significantly underrepresented for markers on chromosomes 1 and 8 ,

Table 2 Segregation* of genetic markers in $\mathrm{F}_{2}$ 's and backcrosses among the maize inbred lines T232 and CM37

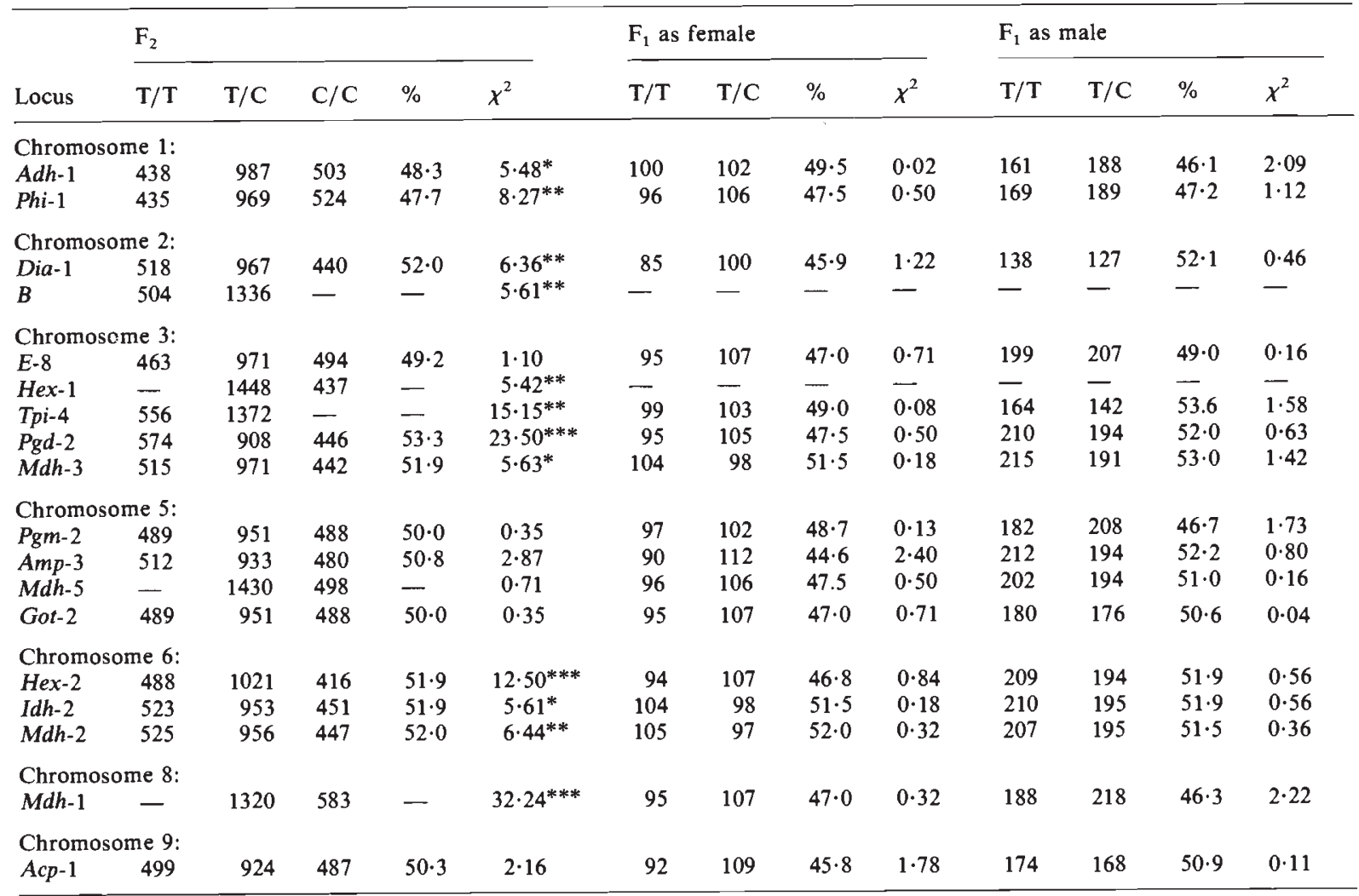

* $N=1928,202$, and 402 for the $F_{2}, B C$ with $F_{1}$ as female, and $B C$ with $F_{1}$ as male families, respectively, although some loci in some individuals were not scored. The designations $\mathrm{T} / \mathrm{T}, \mathrm{T} / \mathrm{C}$, and $\mathrm{C} / \mathrm{C}$ refer to homozygosity for the $\mathrm{T} 232$ allele, heterozygosity, and homozygosity for the CM37 allele, respectively. Percent T232 representation in the progenies (where calculable) is also indicated (\%). Expected ratios were $1: 1$ in the BC's and $1: 2: 1$ in the $\mathrm{F}_{2}$, except for the loci $\mathrm{B}, H e x-1, T p i-4, M d h-5$, and $M d h-1$, where the expected ratio was $3: 1$. Significance levels for departure from expectations are $0 \cdot 10(*), 0 \cdot 05(* *)$, and $0.01(* * *)$. 
whereas nine of the ten segregating loci on chromosomes 2, 3, and 6 were deficient for the allele contributed by CM37.

A number of observations indicate that the mechanisms underlying the observed segregation distortion are pre-zygotic in nature: (a) All ears appeared full without any visible evidence of ovule abortion; (b) Seed germination was nearly perfect (>99 per cent); (c) Electrophoretic analyses were conducted on 5-day-old seedlings, prior to any opportunity for post-zygotic selection to occur. This evidence suggests that the causal processes were manifested in gametes produced by the $F_{1}$ parent, and may be broadly construed as suggesting some type of gamete competition. Whatever the physiological basis of the phenomenon, it is clear from the data of table 2 that gametic selection has occurred, and that it has a complex multilocus and multi-chromosomal genetic origin. It is additionally evident that a minimum of five genetic factors were involved, one on each of the chromosomes $1,2,3,6$, and 8 . Because only 40 per cent of the genome was covered by the segregating markers (Edwards et al., 1986), it seems probable that additional factors were present that went undetected. While the data of table 2 do not allow mapping of the detected factors, it is possible to speculate about their general chromosomal location in some cases. If one makes the simplifying assumption that all distortions on a chromosome are due to the action of a single factor, the magnitude of distortion for linked marker loci will be a function of the recombination distance between the factor and the marker. Based on the relative magnitudes of segregation distortion for multiple markers on chromosome 3 , for example, one might hypothesise that one gametic factor is located near Tpi-4 or Pgd-2 (which are 10 map units apart).

Because the sexual origin of the gametes forming the $F_{2}$ could not be discerned, and because there was evidence suggesting complex gamete competition arising from factors contributed by both parents, backcross progenies were examined with the aim of partitioning the observed $F_{2}$ distortions into male and female components. Surprisingly, all loci in both families (using the $F_{1}$ as male and as female) segregated according to expectations (Table 2). We have little explanation for this apparent loss of the distortion phenomena. The sample sizes employed were sufficient to detect significant departures from expectations for many loci if skewed segregation occurred with the same magnitude observed in the $F_{2}$. Because all progenies contained the same cytoplasm, differential nuclear-cytoplasmic interactions can be ruled out.
It should be noted that the $\mathrm{F}_{2}$ and $\mathrm{BC}$ families were produced in different environments and seasons, with the former generated in a winter nursery in Florida and the latter generated in North Carolina in the summer. The presence of significant gamete competition in one environment and not in another suggests the possibility that environmental selection, rather than environmentally independent physiological or genetic selection, was a primary determinant of the observed segregation distortions in the $\mathrm{F}_{2}$, and additionally suggests that its selective influence varied markedly in magnitude between the two environments. Such an interpretation would have some precedent, in that differential gamete transmission with varying environmental features has been previously noted (Herrero and Johnson, 1980; Zamir et al., 1982).

One might legitimately question whether or not segregation distortion on the scale reported here is more frequent than is commonly believed. Multilocus distorted segregation frequently arises in interspecific crosses (Stephens, 1949; Vallejos and Tanksley, 1983), but has been rarely reported within a species. It seems probable that additional infraspecific examples will become evident as others examine numerous non-deleterious and ostensibly neutral markers in large progenies. We have examined a similarly sized F2 of the inbreds Tx303 and C0159, and all 18 markers fit Mendelian expectations, as did most markers in six additional F2's of average sample size 500 (data not presented). It may be that the inbreds used in the present study, T232 and CM37, which are rather divergent in pedigree, are polymorphic at a larger than average number of genetic loci influencing gamete biology.

Acknowledgements This paper is a joint contribution from the USDA, ARS and North Carolina State University. Supported by USDA Competitive Research Grant 83-CRCR-1-1273 and NIH Research Grant \# GM 11546 from the National Institute of General Medical Sciences of the USA. Paper No. 10549 of the Journal Series of the North Carolina Agricultural Research Service, Raleigh, NC.

\section{REFERENCES}

BIANCHI, A. AND LORENZONI, C. 1975. Gametophyte factors in Zea mays. Mulcahy, D. L. (ed.) In Gamete Competition in Plants and Animals, North Holland, Amsterdam.

CARDY, B. J., STUBER. C. W., WENDEL, J. F. AND GOODMAN, M. M. 1983. Techniques for starch gel electrophoresis of enzymes from maize (Zea mays L.). Revised edition. Institute of statistics mimeograph series No. 1317, North Carolina State University, Raleigh. 
EDWARDS, M. D., STUBER, C. W. AND WENDEL, J. F. 1986. Molecular marker facilitated investigations of quantitative trait loci in maize: I. Numbers, geno1:ic distribution, and types of gene action. Genetics, (in press).

EMERSON, R. A. 1934. Relation of the differential fertilization genes, $\mathrm{Ga}$ ga, to certain other genes of the Su-Tu linkage group of maize. Genetics, 19, 137-156.

GOODMAN, M. M. AND STUBER, C. W. 1983. Maize. In Tanksley, S. D. and Orton, T. J. (eds.), Isozymes in Plant Genetics and Breeding, Part B, Elsevier, Amsterdam.

GOODMAN, M. M., STUBER, C. W., NEWTON, K. AND WEISSINGER, H. H. 1980. Linkage relationships of 19 enzyme loci in maize. Genetics, 96, 697-710.

GRANT, v. 1975. Genetics of Flowering Plants, Columbia University Press, New York.

HERRERO, M. P., AND JOHNSON, R. R. 1980. High temperature stress and pollen viability of maize. Crop Science, 20, 796-800.

JOHNSON, C. M. AND MULCAHY, L. 1978. Male gametophyte in maize: II. Pollen vigor in inbred plants. Theor. Appl. Genet., 51, 211-215.

LONGLEY, A. E. 1945, Abnormal segregation during megasporgenesis in maize. Genetics, 30, 100-113.

MANGELSDORF, P. C. AND JONES, D. F. 1926. The expression of Mendelian factors in the gametophyte of maize. Genetics, 11, 423-455.

MULCAHY, D. .L. 1974. Adaptive significance of gamete competition. Linskens, H. F. (ed.). In Fertilization of higher plants, North Holland, Amsterdam.

otTAViANo, E., SARI-Gorla, M. AND PE, E. 1982. Male gametophytic selection in maize. Theor. Appl. Genet., 63, 249-254.

PFAHLER, P. L. 1967. Fertilization ability of maize pollen grains. II. Pollen genotype, female sporophyte, and pollen storage interactions. Genetics, 57, 513-521.

PFAHLER, P. L. 1975. Factors affecting male transmission in maize (Zea mays L.). Mulcahy, D. L. (ed.), In Gamete Competition in Plants and Animals, North Holland, Amsterdam.

RHOADES, M. M. 1952. Preferential segregation in maize. Gowen, W. (ed.), In Heterosis, Iowa State College Press, Ames.
RHOADES, M. M. AND DEMPSEY, E. 1986. The effect of abnormal chromosome 10 on preferential segregation and crossing over in maize. Genetics, 53, 989-1020.

RICK, C. M. 1963. Differential zygotic lethality in a tomato species hybrid. Genetics, 48, 1497-1507.

SPRAGUe, G. F. 1933. Pollen tube establishment and the deficiency of waxy seeds in certain maize crosses. Proc. Natl. Acad. Sci., 19, 838-841.

STEPHENS, S. G. 1949. The cytogenetics of speciation in Gossypium. 1. Selective elimination of the donor parent genotype in interspecific backcrosses. Genetics, 34, 627637.

STUBER, C. W., EDWARDS, M. D. AND WENDEL, J. F. 1986. Molecular marker facilitated investigations of quantitative trait loci in maize: II. Factors influencing yield and its component traits. Crop $S c i$. (in press).

STUBER, C. W. AND GOODMAN, M. M. 1983a. Allozyme genotypes for popular and historically important inbred lines of corn, Zea mays L. USDA, ARS, Agric. Res. Results, Southern Series, No. 16.

STUBER, C. W. AND GOODMAN, M. M. 1983b. Inheritance, intracellular localization, and genetic variation of phosphoglucomutase isozymes in maize (Zea mays L.) Biochem. Genet., 21, 667-689.

SUITER, K. A., WENDEL, J. F. AND CASE, J. S. 1983. Linkage-1: A Pascal computer program for the detection and analysis of genetic linkage. J. Hered., 74, 203-204.

VALLEJOS, C. E. AND TANKSLEY, S. D. 1983. Segregation of isozyme markers and cold tolerance in an interspecific backcross of tomato. Theor. Appl. Genet., 66, 241-247.

WENDEL, J. F., STUBER, C. W. AND GOODMAN, M. M. 1985. Mapping data for 34 isozyme loci currently being studied. Maize Genet. Coop. Newsl., 59, 90.

WENDEL, J. E., STUBER, C. W., GOODMAN, M. M. AND EDWARDS, M. D. 1986. Duplicated chromosome segments in Zea Mays L.: further evidence from hexokinase isozymes. Theor. Appl. Genet., 72, 178-185.

ZAMIR, D., TANKSLEY, S. D. AND JONES, R. A. 1982. Haploid selection for low temperature tolerance of tomato pollen. Genetics, 101, 129-137. 